\title{
Adsorption Structure and Mechanism of Styryl Phosphoric Acid at the Rutile-Water Interface
}

\author{
Wei Xiao $^{1,2}{ }^{10}$, Fen Jiao ${ }^{1,2}$, Hongbo Zhao ${ }^{1,2, *(1)}$, Wenqing Qin ${ }^{1,2}$, Guanzhou Qiu ${ }^{1,2}$ and \\ Jun Wang 1,2,* \\ 1 School of Minerals Processing \& Bioengineering, Central South University, Changsha 410083, China; \\ xiaowei2015@yahoo.com (W.X.); jfen0601@126.com (F.J.); qinwenqing369@126.com (W.Q.); \\ qgz@csu.edu.cn (G.Q.) \\ 2 Key Laboratory of Biohydrometallurgy of Ministry of Education, Changsha 410083, China \\ * Correspondence: alexandercsu@126.com (H.Z.); wjwq2000@126.com (J.W.); \\ Tel.: +86-0731-8887-6557 (H.Z. \& J.W.)
}

Received: 21 July 2018; Accepted: 17 August 2018; Published: 20 August 2018

\begin{abstract}
The microstructure and mechanism of styryl phosphoric acid (SPA) adsorbed at the rutile-water interface were investigated through zeta potential measurement, ultraviolet-visible spectrophotometry (UV-Vis), Fourier transform infrared spectroscopy (FT-IR) and X-ray photoelectron spectroscopy (XPS). The results of the zeta potential measurement illustrate that SPA is mainly electrostatically adsorbed on the rutile surface, and the adsorption process and result can be well fitted by the Stern-Grahame equation. The adsorption is severely affected by $\mathrm{pH}$ due to different species of SPA occurring in different $\mathrm{pH}$ solutions. The compound of $\mathrm{P}-\mathrm{O}-\mathrm{Ti}$, with a structure of bidentate binuclear or bidentate mononuclear complexes, is formed after SPA is adsorbed on the rutile surface. SPA can be adsorbed on the rutile surface through the coordination of self-polymerization and bidentate mononuclear, which greatly increases the hydrophobicity of the rutile surface. Based on the above analysis and discussion, we proposed the adsorption model of SPA at the rutile-water interface, which was conducive to the modification and synthesis of a highly efficient flotation collector of the primary rutile ore.
\end{abstract}

Keywords: microstructure; electrostatic adsorption; chemical adsorption; surface hydroxylation

\section{Introduction}

Recently, the titanium industry has become more and more important and popular due to its extensive applications in medicine, navigation, aerospace, functional materials, and catalytic industries [1-6]. In the contemporary industrial system, titanium metallurgy sponge and titanium metal use rutile $\left(\mathrm{TiO}_{2}\right)$ and ilmenite $\left(\mathrm{FeTiO}_{3}\right)$ as raw materials. Compared with ilmenite, the titanium in rutile is relatively easy to utilize, with a natural advantage in quality. Therefore, many studies have begun to focus on rutile beneficiation [7-10]. The majority of rutile ores are refractory ores, the concentration of which is very difficult to gauge due to the fine grain sizes associated with the gangues, the complexity of the mineralogy, and the brittleness leading to it being easily over-ground [11]. Although the concentration of rutile ores is obtained by combining gravity, magnetic, and electrostatic separation techniques, flotation is one of the most efficient solutions to the issue [8].

In rutile flotation, sodium oleate, water-soluble petroleum sulfonate, styryl phosphoric acid (SPA), benzyl arsenic acid, alkyl imino bismethylene phosphoric acid and hydroximic acid are commonly used as collectors, and SPA is considered to be the most selective collector for rutile [12-18].

More and more mineral processing researchers are paying attention to the relationship between the adsorption of the collector at the mineral-water interface, and flotation recovery [19-21]. 
Many scholars have tried to explain the adsorption mechanism of collectors on mineral surfaces in the general formation of hydrogen bond adsorption, electrostatic adsorption and complex reaction adsorption [22-29].

It is of great significance to study the adsorption mechanism of collectors at the rutile-water interface, for the development and utilization of rutile $[8,9,15]$. Only when the adsorption mechanism of the collector on the mineral surface is clear enough can a flotation collector with low toxicity and high efficiency be designed by changing the functional group and carbon chain length. Madeley et al. [14] used anionic and cationic collectors as the collector for the flotation of natural rutile, indicating the rate of flotation was influenced by the length of the carbon chain associated with the collecting ions. Fuerstenau et al. [30] explained the adsorption phenomena of alkysulfonate at the rutile-water interface with the Stern-Grahame mode of the electrical double layer. Wang et al. [8] reported the flotation behavior and the mechanism of rutile with nonyl hydroxamic acid. The FT-IR results showed chemical adsorption identified on the rutile surface where a chelate of $\mathrm{O}$, O-five-membered rings with $\mathrm{Ti}^{4+}$ may form on the rutile surface. The density functional theory (DFT) calculation was used to study the adsorption behaviors of carboxylic acid at rutile $\mathrm{TiO}_{2}$ (110) [31]. The calculation results showed that carboxylic acid preferred to be dissociatively adsorbed in a bridging bidentate configuration and induced significant surface relaxation at the adsorption sites, which also influenced other close surface atoms. Liu et al. [12] found that among the collectors of rutile flotation, such as benzyl arsenic acid, sodium oleate, sodium dodecyl sulphate, amino acids, diohosphonic acid, and styryl phosphoric acid (SPA), SPA was the most effective and aliphatic alcohol (e.g., octanol) was required to maintain the effectiveness. However, the mechanism of interaction between SPA and the rutile surface has rarely been reported. Peng [13] used angle resolution X-ray photoelectron spectroscopy (ARXPS) to study the effect of the interaction between SPA and octanol on rutile flotation and found that octanol associated with SPA pointed their long hydrocarbon chains towards bulk solution, while SPA was chemically adsorbed on the rutile surface. However, this literature does not fundamentally explain the mechanism of interaction between the collector and the rutile surface, especially at the molecular level of interpretation.

This paper attempts to explain the mechanism of interaction between SPA and the rutile surface using zeta potential measurement, UV-Vis, FT-IR, and XPS at the molecular level, and derived the adsorption model of SPA at the rutile-water interface. The present results are expected to be conducive to the understanding of the interaction mechanism between rutile and SPA and provide theoretical support for the development of a highly efficient flotation collector for primary rutile ores. However, model selection uncertainly exists in these models. In the future, we can assist DFT calculations and X-ray Absorption Fine Structure (XAFS) technology yet to be determined.

\section{Materials and Methods}

\subsection{Materials and Reagents}

The pure rutile samples used for the mechanism analysis were taken from Zaoyang Mine in Hubei, China, and then crushed, from which the rutile minerals were picked by hand. The handpicked rutile minerals were ground with a ceramic ball mill. The products after grinding were screened by 0.074 and $0.038 \mathrm{~mm}$ sieves, respectively. Those above $0.074 \mathrm{~mm}$ were returned to the ceramic ball mill for re-grinding, while those below $0.038 \mathrm{~mm}$ were stored as overcrushing samples. Particles from 0.038 to $0.074 \mathrm{~mm}$ were stored as experimental samples, and then purified by several magnetic separations, re-election impurity, and wet sieve. Finally, the particles were repeatedly cleaned using deionized water and dried at a low temperature as a flotation sample. The crystal phase composition was determined by X-ray diffraction (D8 Advance, Bruker, Karlsruhe, Germany), whose detailed processes and methods were previously described by Han [32]. The chemical composition of the rutile samples was measured by a wavelength dispersive X-ray fluorescence (XRF) spectrometer S4 Pioneer (PANalytical B.V., Almelo, The Netherlands). The XRD and XRF results are presented in Figure 1 and 
Table 1. The former demonstrated that the rutile samples were mainly composed of rutile, and the Ti element only originated from the rutile mineral. Therefore, according to the element content of XRF shown in Table 1, the purity of the rutile mineral sample was calculated to be $93.8 \%$ with small impurities of $2.17 \% \mathrm{SiO}_{2}$ and $2.86 \%$ iron oxide.

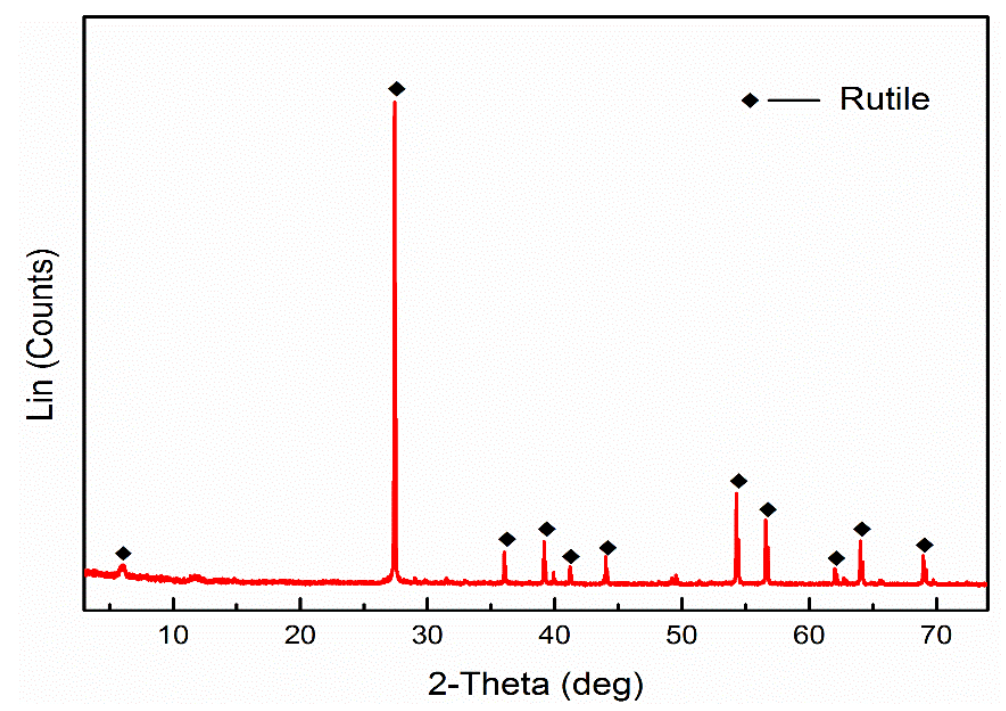

Figure 1. XRD pattern of the rutile.

Table 1. Multi-element analysis of the pure rutile mineral (\%).

\begin{tabular}{cccccccc}
\hline Element & $\mathrm{TiO}_{2}$ & $\mathrm{FeO}$ & $\mathrm{Fe}_{2} \mathrm{O}_{3}$ & $\mathrm{SiO}_{2}$ & $\mathrm{CaO}$ & $\mathrm{MgO}$ & $\mathrm{Al}_{2} \mathrm{O}_{3}$ \\
\hline Content & 93.80 & 1.53 & 1.33 & 2.17 & 0.17 & 0.31 & 0.99 \\
\hline
\end{tabular}

Hydrochloric acid (analytical grade), sodium hydroxide (analytical grade) and potassium bromide (spectroscopically grade) were purchased from Sinopharm Chemical Reagent Co., Ltd. (Shanghai, China). Styryl phosphoric acid (SPA) with 68\% purity was obtained from Zhuzhou Flotation Reagents, and then purified by recrystallization in methanol-water solvent in the laboratory. Its recrystallization product (95\% purity) was used in all experiments. All aqueous solutions were prepared using Milli-Q water (Millipore deionized, 18.2 $\mathrm{M} \Omega$ resistivity).

\subsection{Methods}

\subsubsection{Zeta Potential Measurements}

The zeta potential on the rutile surface was determined with a ZetaSizer 3000 Malvern Instrument (Malvern Instrument, Malvern, UK). The overcrushing samples were ground to less than $5 \mu \mathrm{m}$ by agate grinding. The suspension was prepared by adding $20 \pm 1 \mathrm{mg}$ of $\mathrm{TiO}_{2}$ to $50 \mathrm{~mL}$ of distilled, deionized water containing $10^{-3} \mathrm{~mol} / \mathrm{L} \mathrm{KCl}$ as a supporting electrolyte. The suspension was conditioned for $15 \mathrm{~min}$, and the $\mathrm{pH}$ was measured and then adjusted using $\mathrm{NaOH}$ or $\mathrm{HCl}$ in the $\mathrm{pH}$ range of 2-11. Suspensions without or with 200 or $400 \mathrm{mg} / \mathrm{L}$ of SPA were placed on a rotating shaker for $30 \mathrm{~min}$. The zeta potential was measured in accordance with the procedures described in the instrument manual. The reported results were the average of at least three full repeats of the experiment.

\subsubsection{Adsorption Experiments}

The SPA adsorption experiment was carried out using $2.000 \pm 0.010 \mathrm{~g}$ of experimental samples. The aqueous solutions with $0-400 \mathrm{mg} / \mathrm{L}$ of SPA were added in sequence to the rutile samples in $100 \mathrm{~mL}$ 
centrifuge tubes with $40 \mathrm{~mL}$ of liquid. Adsorption experiments were performed at the $\mathrm{pH}$ of 2.3 and 4.1 , respectively. The samples were shaken with a centrifugal speed of $100 \mathrm{rpm}$ for $12 \mathrm{~h}$ to achieve the equilibrium of adsorption determined with the preliminary test. Finally, the solid supernatants and sorbents were obtained from the slurry solution by filtering. The supernatants were analyzed through UV spectroscopy (UV-9100, Shimazu, Kyoto, Japan), and the adsorption capacity of SPA was calculated by the difference between the initial and equilibrium final concentrations, allowing us to determine the adsorption isotherms for SPA on the rutile mineral.

The experimental results were analyzed using Freundlich isotherms, as in the following Equation (1):

$$
\log q_{e}=\log K_{F}+n_{f} \log C_{e}
$$

where $C_{e}$ is the equilibrium concentration of SPA in the liquid phase $(\mathrm{mg} / \mathrm{L}), q_{e}$ is the equilibrium concentration of SPA in the solid phase $(\mathrm{mg} / \mathrm{g}), K_{F}$ is the adsorption amount constant of the Freundlich model $\left(\mathrm{mg}^{1 / \mathrm{n}} \cdot \mathrm{L}^{1 / \mathrm{n}} \cdot \mathrm{g}^{-1}\right)$, and $n_{f}$ is the adsorption intensity constant of the Freundlich model.

The adsorption process of organic compounds on mineral particles is usually studied through Freundlich isotherms [33,34]. The Freundlich equation is an isotherm model that represents the adsorbent surface as heterogeneous [35]. Based on experimental data, the parameters of $K_{F}$ and $n_{f}$ were fitted according to the Freundlich isotherm model (Equation (1)) by means of the least square fitting technique, using nonlinear regression and the origin package software (Version 8.5).

\subsubsection{FT-IR Spectroscopy of Rutile-SPA Complexes}

FT-IR spectra of rutile, SPA and rutile-SPA complexes were recorded to examine the functional groups of rutile before and after adsorbing SPA. The experimental samples of $2.00 \mathrm{~g}$ were added into the $100 \mathrm{~mL}$ centrifuge tube with $40 \mathrm{~mL}$ of liquid, where the concentration of SPA was $8000 \mathrm{mg} / \mathrm{L}$ (400 mg/L $\times 20$ times). By this time, the slurry $\mathrm{pH}$ was 2.3. Then, the samples were shaken at a centrifugal speed of $100 \mathrm{rpm}$ for $30 \mathrm{~min}$. FT-IR spectra were recorded over the region of $600-4000 \mathrm{~cm}^{-1}$. The samples were examined in $\mathrm{KBr}$ pellets ( $3 \mathrm{mg} / 300 \mathrm{mg} \mathrm{KBr}$ ). All samples were analyzed with a Lumex FTIR-08 spectrophotometer (PerkinElmer, Waltham, MA, USA).

\subsubsection{XPS Measurements}

The chemical compositions of the rutile surfaces were determined by XPS on a Thermo Scientific ESCALAB 250Xi (Thermo Fisher Scientific, Waltham, MA, USA), using an Al K $\alpha$ X-ray source operated at $200 \mathrm{~W}$ with $20 \mathrm{eV}$ pass energy. The sample preparation method was the same as that of the FT-IR spectra experiment (the SPA concentration was $400 \mathrm{mg} / \mathrm{L}$, and the $\mathrm{pH}$ value was 2.3) with the vacuum pressure ranging from $10^{-9}$ to $10^{-8}$ Torr and a takeoff angle of $90^{\circ}$, which was used for collecting and analyzing data using the MultiPak spectrum software (Version 9.0) [36,37].

\section{Results and Discussion}

\subsection{Zeta Potentials of the $\mathrm{TiO}_{2}$ Surface}

The adsorption of anions onto a mineral inevitably leads to a change in the surface charge [38,39]. Figure 2 shows the zeta potentials of the $\mathrm{TiO}_{2}$ surface as a function of $\mathrm{pH}$ in the presence and absence of 200 or $400 \mathrm{mg} / \mathrm{L}$ of SPA. The obtained zeta potentials ranged from $20 \mathrm{mV}$ to $-35 \mathrm{mV}$. The isoelectric point (IEP) of the $\mathrm{TiO}_{2}$ sample occurred at $\mathrm{pH} 4.5$ where the net surface charge was zero, which is very consistent with the previously reported data [40].

The IEP of the $\mathrm{TiO}_{2}$ surface shifted from 4.5 to 2.7 with the increase of the SPA concentration, and the zeta potentials showed negative values in the studied range of $\mathrm{pH}$ (from 2 to 9) even when the SPA total concentration in the solution was $400 \mathrm{mg} / \mathrm{L}$. The shift of IEP to a lower pH value proved that anionic negatively charged surface complexes were formed [41]. Therefore, the results of the zeta potential measurement indicate that SPA is adsorbed on the $\mathrm{TiO}_{2}$ surface in the form of negatively charged inner-sphere complexes. The formation of negatively charged SPA surface complexes can 
be expected in advance because anionic $\mathrm{C}_{6} \mathrm{H}_{5} \mathrm{C}_{2} \mathrm{H}_{2} \mathrm{PO}_{3} \mathrm{H}^{-}$is the predominant SPA species in the $\mathrm{pH}$ range of 2 to 7.5, as shown in Figure 3. Therefore, the change of the isoelectric point on the surface of rutile in this experiment occurred fundamentally because the $\mathrm{OH}^{-}$ion in the hydroxylation of the rutile surface was replaced by the $\mathrm{C}_{6} \mathrm{H}_{5} \mathrm{C}_{2} \mathrm{H}_{2} \mathrm{PO}_{3} \mathrm{H}^{-}$anionic. Thus, the process of the deprotonation of the rutile surface hydroxyl group is realized. Electrostatic adsorption may take place in the form of ion exchange that involves the displacement of similarly charged ionic species from the surfaces of the minerals [26].

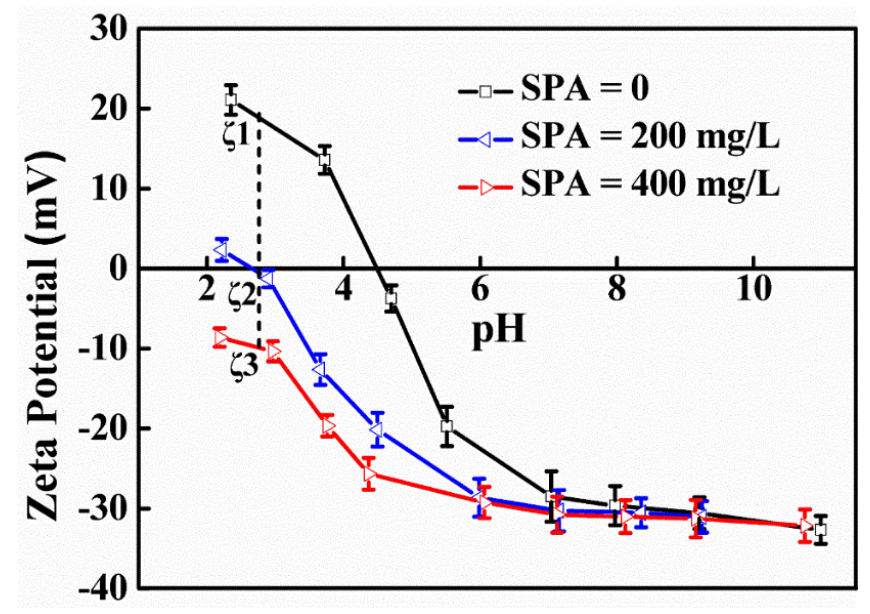

Figure 2. Zeta potential of $\mathrm{TiO}_{2}$ as a function of $\mathrm{pH}$ and total SPA concentration in $10^{-3} \mathrm{~mol} / \mathrm{L}$ $\mathrm{KCl}$ solution.

The experiment was based on batch studies and showed negligible sorption of SPA in the alkaline solution, which was caused by a strong competition between the anionic $\mathrm{C}_{6} \mathrm{H}_{5} \mathrm{C}_{2} \mathrm{H}_{2} \mathrm{PO}_{3} \mathrm{H}^{-}$and $\mathrm{OH}^{-}$ on the $\mathrm{TiO}_{2}$ surface in the alkaline solution. The result of this competition suggests that SPA could not be adsorbed on the $\mathrm{TiO}_{2}$ surface in the alkaline solution, thus the form of SPA adsorption on the $\mathrm{TiO}_{2}$ surface may be primarily electrostatic adsorption.

The adsorption density of collector ions, which was dominant with electrostatic adsorption, can be calculated using the Stern-Grahame Equation [42]:

$$
\Gamma=\mathrm{k} C \exp \left(-\frac{\Delta G_{a d s}^{o}}{\mathrm{RT}}\right)
$$

where $\mathrm{k}$ (constant, and less than 1) is the adsorption coefficient; $C$ is the collector concentration in aqueous solution; $\mathrm{R}$ is the gas constant; $T$ is the absolute temperature; and $\Delta G_{a d s}^{o}$ is the standard free energy of adsorption. $\Delta G_{a d s}^{o}$ is estimated by the following Equation:

$$
\Delta G_{a d s}^{o}=\mathrm{ZF} \Delta \zeta
$$

where $\mathrm{Z}$ is the valence of the adsorption ions ( $\mathrm{Z}=1$ for SPA at $\mathrm{pH} 2.7)$; $F$ is the Faraday constant; and $\Delta \zeta$ is the difference value in zeta potential before and after the collector is adsorbed.

Based on the results in Figure 2, the adsorption density and standard free energy of SPA are shown in Table 2. $\Delta G_{a d s}^{o}$ was a negative value in all conditions, indicating that SPA could be spontaneously adsorbed on the rutile surface in all experiments. The value of $\Delta G_{a d s}^{o}$ represented the adsorption capacity of the collector on the mineral surface. The smaller the value, the stronger the adsorption capacity will be. Table 2 shows that the value (-2.82) of $\Delta G_{a d s}^{o}$ for $400 \mathrm{mg} / \mathrm{L}$ of SPA adsorbed on the rutile surface was less than that $(-1.99)$ for $200 \mathrm{mg} / \mathrm{L}$ of SPA. This reveals that the adsorption of $400 \mathrm{mg} / \mathrm{L}$ of SPA was easier than $200 \mathrm{mg} / \mathrm{L}$ of SPA. It is worth noting that the value of $\Delta G_{a d s}^{o}$ for the adsorption difference between $200 \mathrm{mg} / \mathrm{L}$ of SPA and $400 \mathrm{mg} / \mathrm{L}$ of SPA was the smallest of all values, 
which indicates that it may be difficult to continue to adsorb the SPA after a certain amount of SPA has already been adsorbed.

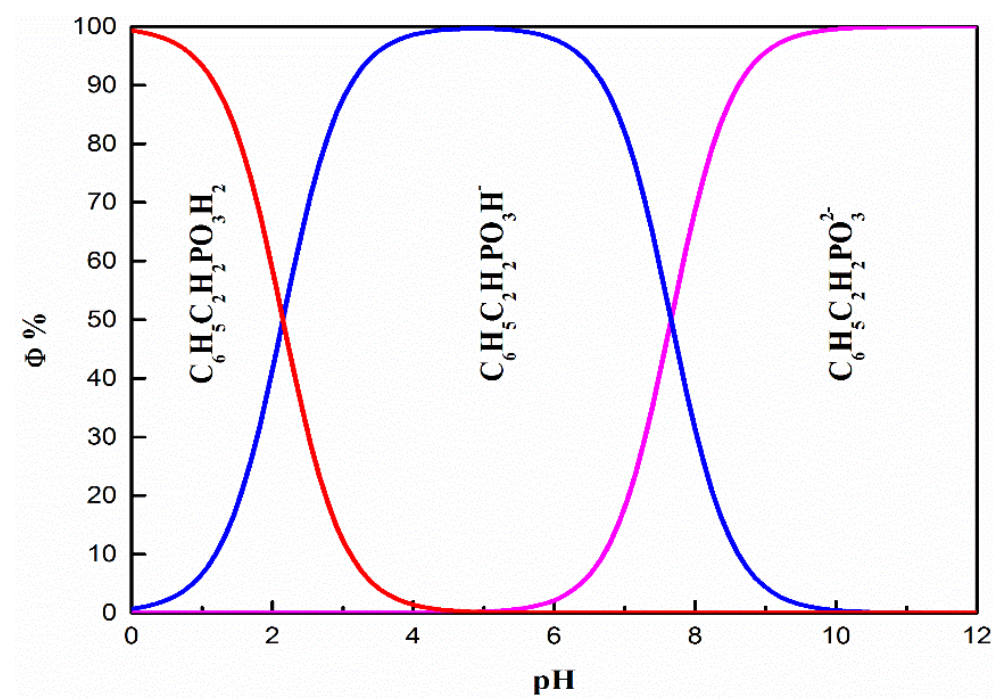

Figure 3. The percentage distribution of SPA species as a function of aqueous $\mathrm{pH}$ values, $\mathrm{K} \alpha 1=2.0$; $\mathrm{K} \alpha 2=7.1$ [43].

Table 2. The results of different parameters at $\mathrm{pH} 2.7$ under various conditions.

\begin{tabular}{cccc}
\hline Condition $^{*}$ & $\boldsymbol{\Delta} \zeta(\mathbf{m V})$ & $\Gamma(\mathbf{m o l} / \mathrm{L})$ & $\Delta G_{\text {ads }}^{\boldsymbol{o}}(\mathbf{k J})$ \\
\hline$\Delta_{1}$ & 20.62 & $\mathrm{kC} \exp (0.000803)$ & -1.99 \\
$\Delta_{2}$ & 29.25 & $\mathrm{kC} \exp (0.00114)$ & -2.82 \\
$\Delta_{3}$ & 8.63 & $\mathrm{kC} \exp (0.000336)$ & -0.83
\end{tabular}

* $\Delta_{1}$ : the adsorption of $200 \mathrm{mg} / \mathrm{L} \mathrm{SPA} ; \Delta_{2}$ : the adsorption of $400 \mathrm{mg} / \mathrm{L} \mathrm{SPA} ; \Delta_{3}$ : the adsorption difference between 200 and $400 \mathrm{mg} / \mathrm{L} \mathrm{SPA} ; \zeta_{1}=19.35 \mathrm{mV}, \zeta_{2}=-1.27 \mathrm{mV}, \zeta_{3}=-9.91 \mathrm{mV} ; \Delta \zeta_{1}=\zeta_{1}-\zeta_{2}, \Delta \zeta_{2}=\zeta_{1}-\zeta_{3}, \Delta \zeta_{3}=\zeta_{2}-\zeta_{3}$.

\subsection{Adsorption Isotherms}

Figure 4 shows the adsorption isotherms and values of the Freundlich parameter $\left(K_{F}\right.$ and $\left.n_{f}\right)$ for SPA adsorption on the $\mathrm{TiO}_{2}$ surface. The adsorption isotherms for $\mathrm{SPA}$ on the $\mathrm{TiO}_{2}$ surface were established in aqueous solution at $\mathrm{pH} 2.3$ and 4.2 at $25^{\circ} \mathrm{C}$. The adsorption data were well fitted to the Freundlich model $(\mathrm{r}>0.99)$.

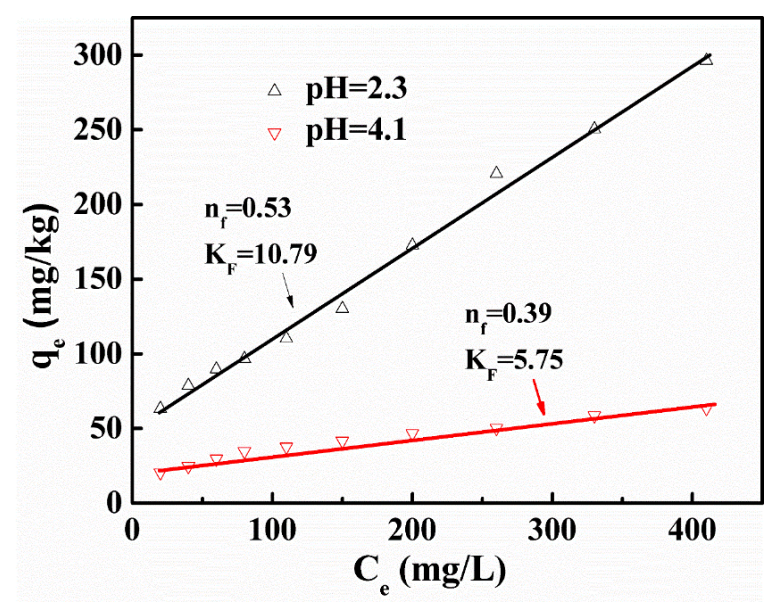

Figure 4. The Freundlich model fittings of SPA adsorption on the rutile surface. 
From Figure 4, it can be seen that the change of $\mathrm{pH}$ values affects the isotherm curves, resulting in a change in the general shape of the isotherm. At $\mathrm{pH} 2.3$, the adsorption amount constant $\left(K_{F}\right)$ and the adsorption intensity constant $\left(n_{f}\right)$ of the Freundlich isotherm model were 10.79 and 0.53 , respectively, while they were 5.75 and 0.39 respectively at $\mathrm{pH}$ 4.1. The change of $K_{F}$ and $n_{f}$ indicates that the adsorption amount and the intensity increase with a decrease in $\mathrm{pH}$, which is consistent with the results of the zeta potential measurement. Koopal et al. found that the adsorption process of ionic surfactants on the metal oxide mineral surface was typically characterized by four regions [44]. In this study, the adsorption process belonged to regions II and III. The difference between the two curves in Figure 4 revealed that $\mathrm{pH}$ played a very significant role in controlling the adsorption of ionic surfactants. Zhang et al. also reached a similar conclusion [27].

\subsection{FT-IR}

The presence of SPA adsorption on the rutile surface is shown in Figure 5, which presents the infrared spectrum of the SPA and the rutile before and after SPA adsorption. The adsorption of SPA is proven by the presence of the functional groups at 1157, 1452 and $2879 \mathrm{~cm}^{-1}$, which correspond to the characteristic peaks of SPA in the infrared spectrum of rutile undergoing SPA adsorption. The peak of $1124 \mathrm{~cm}^{-1}$ on the SPA curve is the characteristic of $\mathrm{P}=\mathrm{O}$, while the peaks of 993 and $957 \mathrm{~cm}^{-1}$ are the characteristic of $\mathrm{P}-\mathrm{O}[45,46]$. However, it is only a peak of $1157 \mathrm{~cm}^{-1}$ at about $957-1124 \mathrm{~cm}^{-1}$ in the (SPA + rutile) curve. Compared with $1157 \mathrm{~cm}^{-1}$, either 1124 or $957-1124 \mathrm{~cm}^{-1}$ has a larger offset, which suggests a change in the chemical environment around the $\mathrm{P}$ and $\mathrm{O}$ atoms. This is because SPA chemically reacts with the Ti atom of the rutile surface, and the bond of $\mathrm{P}-\mathrm{O}-\mathrm{Ti}$ is produced. In the SPA curve, the stretching vibration band of the $\mathrm{O}-\mathrm{H} \cdots \mathrm{O}$ group appears at $2854 \mathrm{~cm}^{-1}$, which peak shifts to $2879 \mathrm{~cm}^{-1}$ after SPA adsorption on the rutile surface. The peak of $2854 \mathrm{~cm}^{-1}$ is relatively wide, while that of $2879 \mathrm{~cm}^{-1}$ is relatively sharp, indicating that the polarity of the $\mathrm{O}-\mathrm{H}$ group has changed. In observing the peak of $2854 \mathrm{~cm}^{-1}$ in the SPA curve and the peak of $2879 \mathrm{~cm}^{-1}$ in the (SPA + rutile) curve, it could be clearly seen that a hydrogen bond forms in the molecular structure of the SPA and rutile surface after SPA adsorption $[47,48]$. In the molecular structure of SPA, there are two hydroxyl groups that could form intramolecular hydrogen bonds and intermolecular hydrogen bonds between SPA and SPA molecular. However, there is a hydrogen atom in the hydroxyl group substituted by the $\mathrm{Ti}$ atom (forming $\mathrm{P}-\mathrm{O}-\mathrm{Ti}$ ) on the rutile surface after SPA adsorption. The hydrogen bonds whose bond structure $(\mathrm{P}-\mathrm{O}-\mathrm{H} \cdots \mathrm{O}-\mathrm{Ti})$ is suggested on the rutile surface may be formed by a hydroxyl group in the SPA molecular with an oxygen atom.

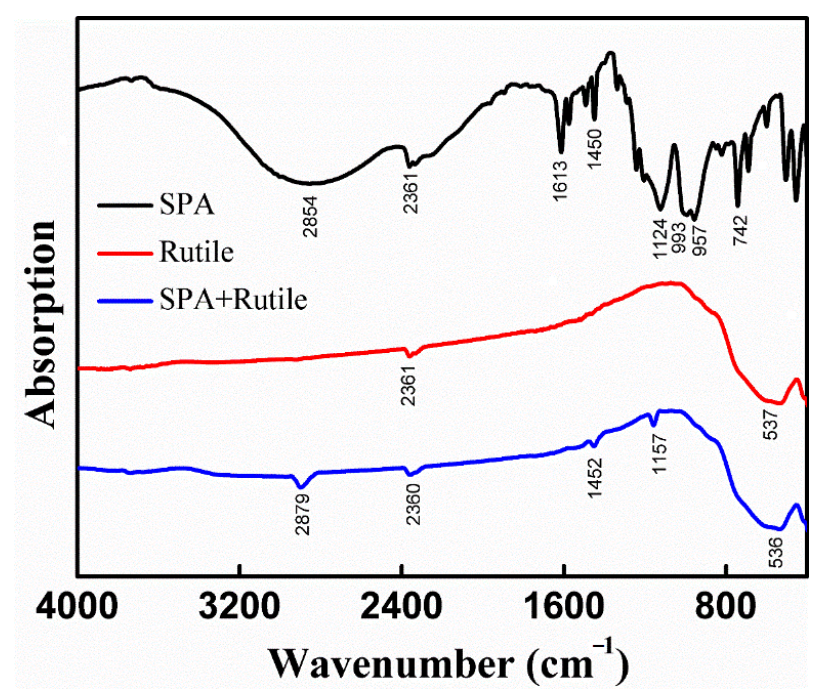

Figure 5. Infrared spectrum of SPA, rutile and rutile with SPA adsorbing treaded (at $\mathrm{pH}=2.3$ ). 
The molecules containing phosphate $\left(\mathrm{PO}(\mathrm{OH})_{2}\right)$ are characterized by the strong adsorption peak at $1613 \mathrm{~cm}^{-1}$ in the SPA spectrum. The stretching vibration of the phenyl group $\left(\mathrm{C}_{6} \mathrm{H}_{5}-\right)$ produces a characteristic intense band at $1452 \mathrm{~cm}^{-1}$ [49]. The peak at $2361 \mathrm{~cm}^{-1}$ is caused by the instrumental noise background. In addition, the characteristic adsorption peak of phosphate $\left(\mathrm{PO}(\mathrm{OH})_{2}\right)$ disappears in the (SPA + rutile) curve, which further proves that SPA chemically reacts with the Ti atom of the rutile surface, and metal-organic salt is produced in the adsorption process. The peak at $537 \mathrm{~cm}^{-1}$ in the rutile curve and the peak at $536 \mathrm{~cm}^{-1}$ in the (SPA + rutile) curve are characteristic of the adsorption of the titanium-oxygen octahedral $[50,51]$, which suggests that the structure of the rutile surface (titanium-oxygen octahedral) did not change after SPA adsorption and thus the chemical bond of Ti-O-P may be formed between $\mathrm{SPA}$ and $\mathrm{TiO}_{2}$. The hydroxylated surface is consistent with the titanium hydroxyl group (Ti-OH) in the analysis of the zeta potential and adsorption capacity.

\subsection{XPS Analysis}

Evidence provided by the FT-IR analysis suggests that the compound of P-O-Ti was formed after SPA adsorption on the rutile surface under acidic conditions. XPS analysis was carried out to further investigate the properties of the rutile surface and the behaviors of SPA adsorption on the rutile surface. The survey and high-resolution photoelectron spectra from the rutile samples before and after SPA adsorption are shown in Figure 6. Table 3 shows the binding energies and chemical shifts of the elements for rutile before and after SPA adsorption. The relative concentrations of the elements, as measured by XPS, are given in Table 4 .
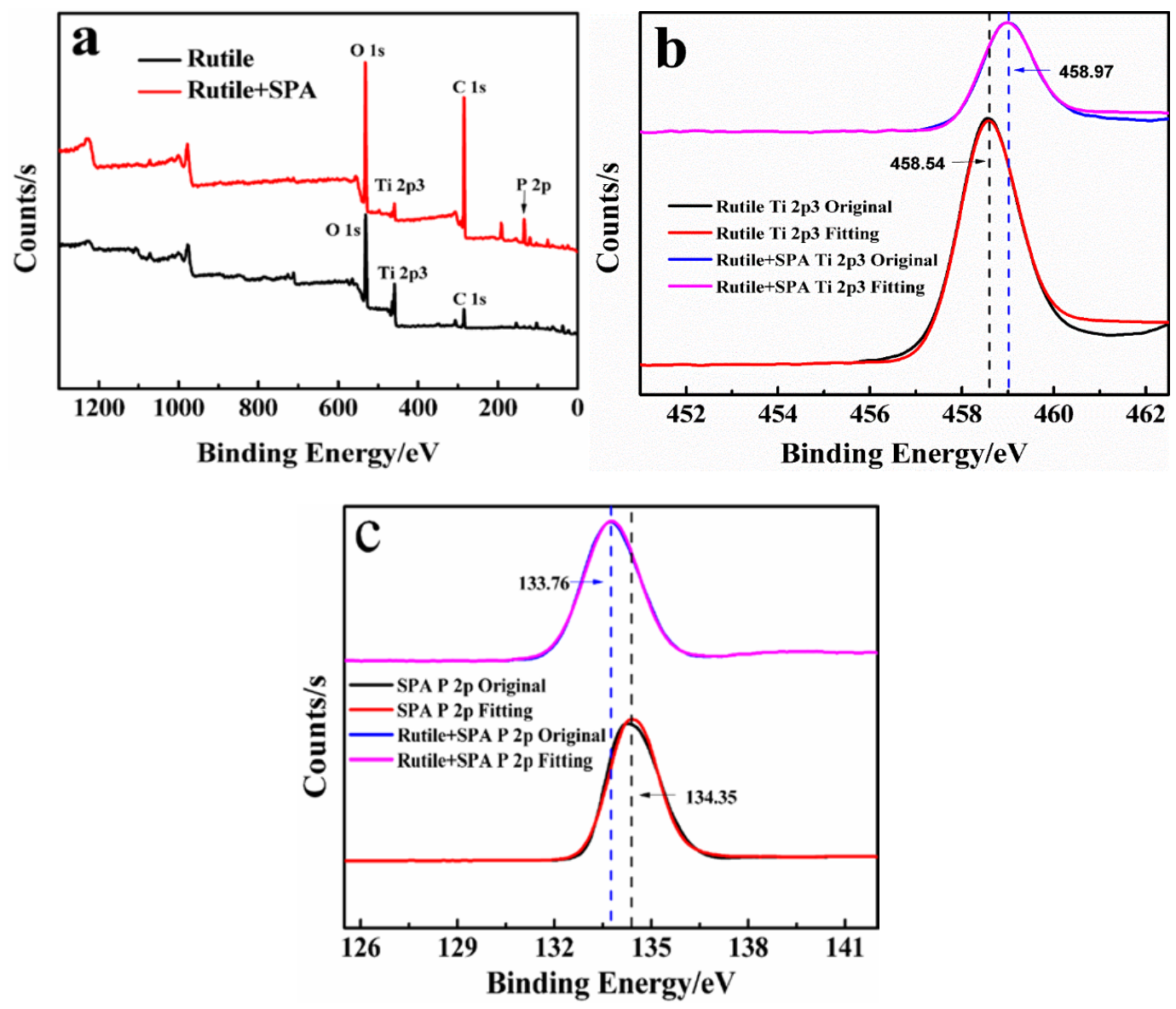

Figure 6. The survey scan and high-resolution X-ray photoelectron spectroscopy (XPS) of rutile before and after SPA adsorption. 
Table 3. Binding energy of elements on the rutile surface before and after SPA adsorbing.

\begin{tabular}{ccccccccc}
\hline \multirow{2}{*}{ Sample } & \multicolumn{4}{c}{ Binging Energy (eV) } & \multicolumn{3}{c}{ Chemical Shift (eV) } \\
\cline { 2 - 9 } & $\mathbf{C}(1 s)$ & $\mathbf{O}(1 s)$ & $\operatorname{Ti}(2 p)$ & $\mathbf{P}(2 p)$ & $\mathbf{C}(1 s)$ & $\mathbf{O}(1 s)$ & $\operatorname{Ti}(2 p)$ & $\mathbf{P}(2 p)$ \\
\hline Rutile & 284.8 & 531.10 & 458.54 & - & - & - & - & - \\
SPA & - & - & - & 34.35 & - & - & - & - \\
Rutile + SPA & 284.9 & 531.49 & 458.97 & 133.76 & +0.1 & +0.39 & +0.43 & -0.59 \\
\hline
\end{tabular}

Table 4. Relative content of elements on the rutile surface.

\begin{tabular}{ccccc}
\hline \multirow{2}{*}{ Sample } & \multicolumn{4}{c}{ Relative Contents (\%) } \\
\cline { 2 - 5 } & $\mathbf{C ( 1 s )}$ & $\mathbf{O}(\mathbf{1 s})$ & Ti(2p) & $\mathbf{P ( 2 p )}$ \\
\hline Rutile & 25.01 & 62.50 & 12.49 & - \\
Rutile + SPA & 51.61 & 36.06 & 4.67 & 6.77 \\
\hline
\end{tabular}

The apparent binding energies of the main Ti $2 p 3$ of rutile and P $2 p$ of organic phosphonate peaks at 458.54 and $134.35 \pm 0.1 \mathrm{eV}[52,53]$, respectively. In addition to the presence of elements that belong to minerals or agents, the presence of adventitious carbon on the mineral surface can also be observed. The relative composition of the natural rutile sample surface primarily includes $\mathrm{C}, \mathrm{O}$, and Ti. A P $2 p$ peak is found in the spectra of the rutile samples after SPA adsorption, but single samples do not appear in rutile. This suggests that SPA could be adsorbed on the rutile surface in some formations, which is consistent with the results of the zeta potential measurement, UV-Vis, and FT-IR analysis. Table 4 shows that the concentration of $\mathrm{P}$ atoms was higher than that of Ti atoms on the rutile surface after SPA adsorption.

In rutile treated with SPA, the binding energies of Ti $2 p$ and $\mathrm{O} 1$ s shifted by $+0.43 \mathrm{eV}$ and $+0.39 \mathrm{eV}$, respectively. This result reveals a chemical interaction between the Ti or $\mathrm{O}$ atom and SPA on the rutile surface. The binding energy peaks of Ti $2 p 3$ were 458.54 and $458.97 \mathrm{eV}$, respectively, which is characteristic of rutile titanium dioxide [54]. Therefore, the conclusion regarding the link between titanium atoms and phosphorus atoms through oxygen atoms ( $\mathrm{P}-\mathrm{O}-\mathrm{Ti})$ is correct. The binding energy shift of Ti $2 p 3$ indicates that a change has taken place in the chemical environment around the Ti atoms. The chemical environment around the Ti atoms in the natural rutile is - Ti-O-Ti- or -Ti-O-H (after it is hydroxylated), but it changes into-Ti-O-P- after being treated with SPA. The electronegative value of the $\mathrm{P}$ atoms is greater than that of the Ti and $\mathrm{H}$ atoms, thus the electron cloud of the Ti and $\mathrm{O}$ atoms significantly shifts to the $\mathrm{P}$ atoms. The electron cloud density of the Ti atoms after being treated with SPA is greater than that of the untreated atoms, which explains why the binding energy of Ti $2 p 3$ after being treated with SPA shifts to high energy $[55,56]$. Conversely, it could also mean that the binding energy of $\mathrm{P} 2 p$ on the rutile surface shifts to low energy after SPA adsorbs on the rutile surface.

\subsection{Establishment and Discussion of Adsorption Models}

Based on the above experimental results and data, the adsorption molecular model of SPA at the rutile-water interface is established, as shown in Figures 7-9. In Figure 7, the molecular structures of SPA adsorption on the rutile surface are shown. He et al. [57] attempted to study the reaction pathway of arsenate adsorption at water- $\mathrm{TiO}_{2}$ interfaces based on the density function theory (DFT), finding that the bidentate binuclear adsorption structure was formed through a monodentate mononuclear metastable-equilibrium adsorption state. Figure 7a shows that SPA forms a bridge-type coordination system with the main adsorption structure of the bidentate binuclear. The bridge-type interaction has been reported in many studies [57]. Pena et al. [58] also found that arsenate formed a compound of $(\mathrm{TiO})_{2} \mathrm{AsO}^{-}$on the surface of $\mathrm{TiO}_{2}$ in the form of bidentate binuclear coordination by extended X-ray absorption fine structure (EXAFS) analyses. However, Wang et al. [8] conjectured that ring-compounds of four or five members coordinating with the bidentate mononuclear were 
formed in the study process of chelates on the surface of rutile adsorption. The molecular structure of $\mathrm{O}, \mathrm{O}-$ four-membered ring-compounds with the bidentate mononuclear is shown in Figure $7 \mathrm{~b}$. The position of the hydrogen bond after SPA adsorption is shown in Figure 8. There may be three kinds of hydrogen bonds [26] in aqueous flotation systems: (1) the hydrogen bonds between the collector and water; (2) the hydrogen bonds between water and the mineral surface; and (3) the hydrogen bonds between collectors and the mineral surface, which are helpful for flotation. As the existence of hydrogen bonds is found by FT-IR spectroscopy on the rutile surface after SPA adsorption, and through the infrared testing process, there is no water involved $[8,59]$. In our study, the hydrogen bonds between collectors and minerals are direct hydrogen bonds between collector functional groups and the surfaces of water solution minerals. In Figure $8 \mathrm{a}$, the model of intramolecular hydrogen bonds is shown. As the phosphate-based polyhydroxy compounds can form intermolecular hydrogen bonds under certain conditions [60], we speculate as to the possibility of intermolecular hydrogen bonds after adsorption in Figure 8b. Figure 9 shows the adsorption models of one Ti atom and two SPA molecules, because the concentration of $\mathrm{P}$ atoms is higher than that of Ti atoms after SPA adsorption. Two models are modified on the basis of the bidentate mononuclear coordination. Due to the self-polymerization between phosphate groups, we present a model in Figure 9a. The adsorption methods in Figure 9 are helpful for the increased hydrophobicity of the rutile surface.
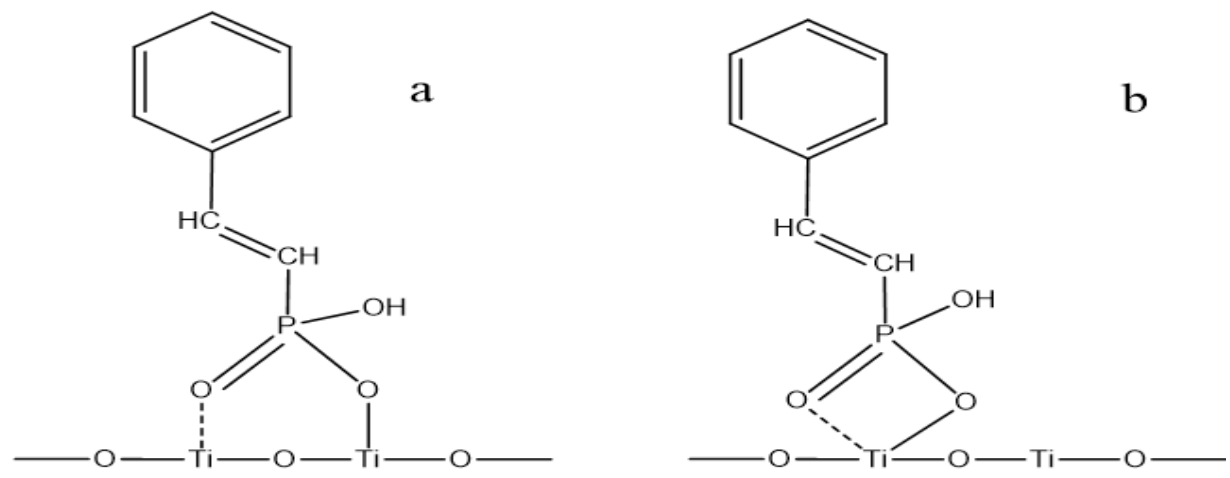

Figure 7. The conjecture of SPA adsorption on the surface of the rutile particle: (a) one SPA molecule binds two Ti atoms; (b) one SPA molecule binds to one atom.

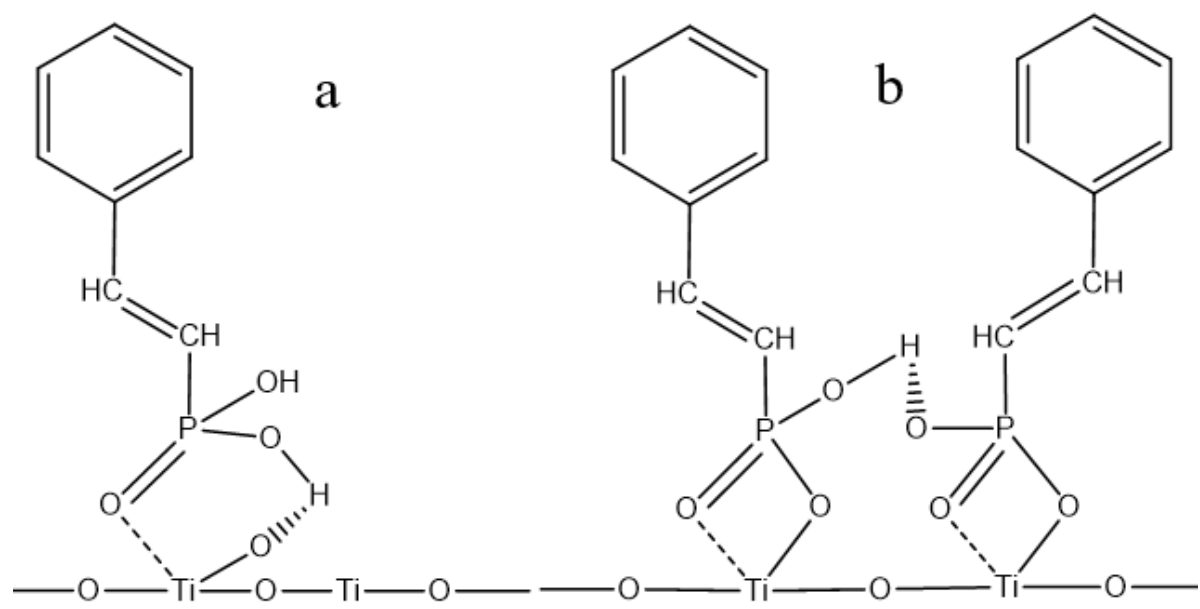

Figure 8. The conjecture of the position of the hydrogen bond after the adsorption of SPA: (a) SPA in the formation of hydrogen bonding $\mathrm{TiO}_{2} ;$ (b) SPA molecules to form hydrogen bonds. 

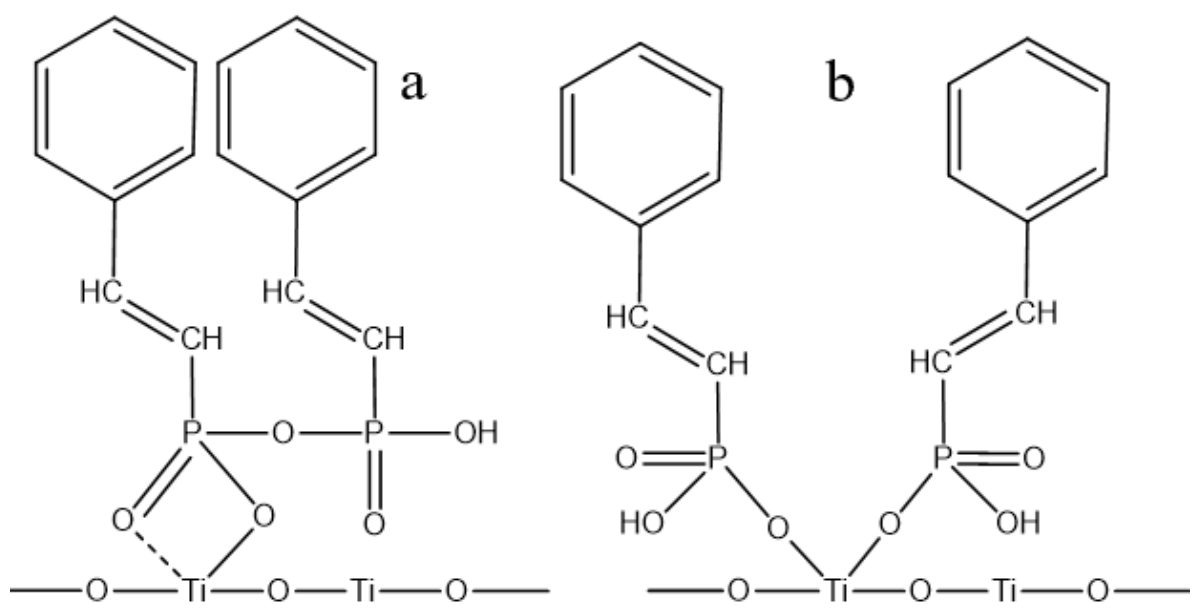

Figure 9. The conjecture of a Ti atom adsorption of two SPA molecular models: (a) two SPA molecules to form polymerization; (b) two SPA molecules are combined with $\mathrm{TiO}_{2}$.

These models in Figures 7-9 reveal the nature of SPA as the most efficient collector for rutile flotation [12]: (1) SPA can stably form the bidentate binuclear or bidentate mononuclear complexes on the surface of rutile; and (2) SPA can be adsorbed on the rutile surface in the form of coordination of the self-polymerization and bidentate mononuclear, greatly increasing the hydrophobicity of the rutile surface.

\section{Conclusions}

On the basis of the zeta potential and UV-Vis measurement, the formation of negatively charged surface complexes of $\mathrm{C}_{6} \mathrm{H}_{5} \mathrm{C}_{2} \mathrm{H}_{2} \mathrm{PO}_{3} \mathrm{H}^{-}$for SPA species adsorbed on the $\mathrm{TiO}_{2}$ surface was determined. SPA was mainly electrostatically adsorbed on the rutile surface, whose adsorption process and result could be well fitted by the Stern-Grahame equation. The adsorption was severely affected by $\mathrm{pH}$, due to different species of SPA occurring in different $\mathrm{pH}$ solutions.

Through FT-IR analysis, it was shown that the compound of P-O-Ti was formed after SPA was adsorbed on the rutile surface under acidic conditions. The hydrogen bond on the rutile surface after SPA adsorption may form by a hydroxyl group in SPA molecular with an oxygen atom on the rutile surface $(\mathrm{P}-\mathrm{O}-\mathrm{H} \cdots \mathrm{O}-\mathrm{Ti})$. The concentration of $\mathrm{P}$ atoms is higher than that of Ti atoms on the rutile surface after XPS analysis. This illustrates that SPA can be adsorbed on the rutile surface in the form of the coordination of self-polymerization and bidentate mononuclear, greatly increasing the hydrophobicity of the rutile surface.

Author Contributions: H.Z. and J.W. conceived of and designed the experiments; W.X. prepared the samples and performed the experiments; W.X., F.J. and H.Z. analyzed the data; and W.X., H.Z., W.Q. and G.Q. contributed to the writing and revising of the paper.

Funding: This research was funded by the National Natural Science Foundation of China (No. 51474254), Yong Elite Scientists Sponsorship Program by CAST (2017QNRC001), Innovation Driven Project of Central South University (2018CX019).

Conflicts of Interest: The authors declare no conflict of interest.

\section{References}

1. Monich, P.R.; Berti, F.V.; Porto, L.M.; Henriques, B.; de Oliveira, A.P.N.; Fredel, M.C.; Souza, J.C.M. Physicochemical and biological assessment of PEEK composites embedding natural amorphous silica fibers for biomedical applications. Mater. Sci. Eng. C 2017, 79, 354-362. [CrossRef] [PubMed]

2. Liu, Y.T.; Zhang, S.Y.; Gao, Y.G. A high-temperature stable antenna array for the satellite navigation system. IEEE Antennas Wirel. Propag. Lett. 2017, 16, 1397-1400. [CrossRef] 
3. Song, J.; Liu, T.; Shi, H.; Yan, S.; Liao, Z.; Liu, Y.; Liu, W.; Peng, Z. Time-frequency analysis of the tribological behaviors of $\mathrm{Ti}_{6} \mathrm{Al}_{4} \mathrm{~V}$ alloy under a dry sliding condition. J. Alloys Compd. 2017, 724, 752-762. [CrossRef]

4. Ye, Z.; Tai, H.; Guo, R.; Yuan, Z.; Liu, C.; Su, Y.; Chen, Z.; Jiang, Y. Excellent ammonia sensing performance of gas sensor based on graphene/titanium dioxide hybrid with improved morphology. Appl. Surf. Sci. 2017, 419,84-90.

5. Kumara, N.T.R.N.; Lim, A.; Lim, C.M.; Petra, M.I.; Ekanayake, P. Recent progress and utilization of natural pigments in dye sensitized solar cells: A review. Renew. Sust. Energ. Rev. 2017, 78, 301-317. [CrossRef]

6. Fontelles-Carceller, O.; Munoz-Batista, M.J.; Conesa, J.C.; Fernandez-Garcia, M.; Kubacka, A. UV and visible hydrogen photo-production using $\mathrm{Pt}$ promoted $\mathrm{Nb}$-doped $\mathrm{TiO}_{2}$ photo-catalysts: Interpreting quantum efficiency. Appl. Catal. B Environ. 2017, 216, 133-145. [CrossRef]

7. Xiao, W.; Cao, P.; Liang, Q.; Peng, H.; Zhao, H.; Qin, W.; Qiu, G.; Wang, J. The activation mechanism of Bi ${ }^{3+}$ ions to rutile flotation in a strong acidic environment. Minerals 2017, 7, 113. [CrossRef]

8. Wang, J.; Cheng, H.; Zhao, H.; Qin, W.; Qiu, G. Flotation behavior and mechanism of rutile with nonyl hydroxamic acid. Rare Met. 2016, 35, 419-424. [CrossRef]

9. Li, H.; Mu, S.; Weng, X.; Zhao, Y.; Song, S. Rutile flotation with $\mathrm{Pb}^{2+}$ ions as activator: Adsorption of $\mathrm{Pb}^{2+}$ at rutile/water interface. Colloid Surf. A Physicochem. Eng. Asp. 2016, 506, 431-437. [CrossRef]

10. Terzi, M.; Kursun, I. Investigation of recovery possibilities of rutile minerals from the feldspar tailings with gravity separation methods. Russ. J. Non-Ferrous Metals 2015, 56, 235-245. [CrossRef]

11. Chachula, F.; Liu, Q. Upgrading a rutile concentrate produced from Athabasca oil sands tailings. Fuel 2003, 82, 929-942. [CrossRef]

12. Liu, Q.; Peng, Y. The development of a composite collector for the flotation of rutile. Miner. Eng. 1999, 12, 1419-1430. [CrossRef]

13. Peng, Y.; Li, Y.; Xu, S. Effect of interactions between styryl phosphoric acid and aliphatic alcohol on rutile flotation. Chin. J. Nonferrous Met. 1999, 9, 358-362. (In Chinese)

14. Madeley, J.D.; Graham, K. Flotation of rutile with anionic and cationic collectors. J. Appl. Chem. 1966, 16, 169-170. [CrossRef]

15. Xiao, W.; Cao, P.; Liang, Q.; Huang, X.; Li, K.; Zhang, Y.; Qin, W.; Qiu, G.; Wang, J. Adsorption behavior and mechanism of $\mathrm{Bi}(\mathrm{III})$ ions on rutile-water interface in the presence of nonyl hydroxamic acid. Trans. Nonferrous Met. Soc. China 2018, 28, 348-355. [CrossRef]

16. Xiao, W.; Fang, C.; Wang, J.; Liang, Q.; Cao, P.; Wang, X.; Zhang, L.; Qiu, G.; Hu, J. The role of EDTA on rutile flotation using $\mathrm{Al}^{3+}$ ions as an activator. RSC Adv. 2018, 8, 4872-4880. [CrossRef]

17. Xiao, W.; Ke, S.; Quan, N.; Zhou, L.; Wang, J.; Zhang, L.; Dong, Y.; Qin, W.; Qiu, G.; Hu, J. The role of nanobubbles in the precipitation and recovery of organic-phosphine-containing beneficiation wastewater. Langmuir 2018, 34, 6217-6224. [CrossRef] [PubMed]

18. Xiao, W.; Zhao, H.; Qin, W.; Qiu, G.; Wang, J. Adsorption mechanism of $\mathrm{Pb}^{2+}$ activator for the flotation of rutile. Minerals 2018, 8, 266. [CrossRef]

19. Kang, J.; Hu, Y.; Sun, W.; Liu, R.; Yin, Z.; Tang, H.; Meng, X.; Zhang, Q.; Liu, H. A significant improvement of scheelite flotation efficiency with etidronic acid. J. Clean Prod. 2018, 180, 858-865. [CrossRef]

20. Jin, S.; Shi, Q.; Li, Q.; Ou, L.; Ouyang, K. Effect of calcium ionic concentrations on the adsorption of carboxymethyl cellulose onto talc surface: Flotation, adsorption and AFM imaging study. Powder Technol. 2018, 331, 155-161. [CrossRef]

21. Yin, Z.; Hu, Y.; Sun, W.; Zhang, C.; He, J.; Xu, Z.; Zou, J.; Guan, C.; Zhang, C.; Guan, Q.; et al. Adsorption mechanism of 4-amino-5-mercapto-1,2,4-triazole as flotation reagent on chalcopyrite. Langmuir 2018, 34, 4071-4083. [CrossRef] [PubMed]

22. Jiang, H.; Sun, Z.; Xu, L.; Hu, Y.; Huang, K.; Zhu, S. A comparison study of the flotation and adsorption behaviors of diaspore and kaolinite with quaternary ammonium collectors. Miner. Eng. 2014, 65, 124-129. [CrossRef]

23. Yang, F.; Sun, W.; Hu, Y.; Long, S. Cationic flotation of scheelite from calcite using quaternary ammonium salts as collector: Adsorption behavior and mechanism. Miner. Eng. 2015, 81, 18-28. [CrossRef]

24. Gao, Z.; Bai, D.; Sun, W.; Cao, X.; Hu, Y. Selective flotation of scheelite from calcite and fluorite using a collector mixture. Miner. Eng. 2015, 72, 23-26. [CrossRef]

25. Deng, L.; Wang, S.; Zhong, H.; Liu, G. N-(6-(hydroxyamino)-6-oxohexyl) decanamide collector: Flotation performance and adsorption mechanism to diaspore. Appl. Surf. Sci. 2015, 347, 79-87. [CrossRef] 
26. Wu, Z.; Wang, X.; Liu, H.; Zhang, H.; Miller, J.D. Some physicochemical aspects of water-soluble mineral flotation. Adv. Colloid Interface Sci. 2016, 235, 190-200. [CrossRef] [PubMed]

27. Zhang, R.; Somasundaran, P. Advances in adsorption of surfactants and their mixtures at solid/solution interfaces. Adv. Colloid Interface Sci. 2006, 123-126, 213-229. [CrossRef] [PubMed]

28. Gao, Z.; Li, C.; Sun, W.; Hu, Y. Anisotropic surface properties of calcite: A consideration of surface broken bonds. Colloid Surf. A Physicochem. Eng. Asp. 2017, 520, 53-61. [CrossRef]

29. Li, C.; Gao, Z. Effect of grinding media on the surface property and flotation behavior of scheelite particles. Powder Technol. 2017, 322, 386-392. [CrossRef]

30. Fuerstenau, D.W.; Jang, H.M. On the nature of alkylsulfonate adsorption at the rutile/water interface. Langmuir 1991, 7, 3138-3143. [CrossRef]

31. Yu, Y.Y.; Gong, X.Q. Unique adsorption behaviors of carboxylic acids at rutile $\mathrm{TiO}_{2}$ (110). Surf. Sci. 2015, 641, 82-90. [CrossRef]

32. Han, J.; Jiao, F.; Liu, W.; Qin, W.; Xu, T.; Xue, K.; Zhang, T. Innovative methodology for comprehensive utilization of spent $\mathrm{MgO}-\mathrm{Cr}_{2} \mathrm{O}_{3}$ bricks: Copper flotation. ACS Sustain. Chem. Eng. 2016, 4, 5503-5510. [CrossRef]

33. Park, S.J.; Yoon, T.I. Effects of iron species and inert minerals on coagulation and direct filtration for humic acid removal. Desalination 2009, 239, 146-158. [CrossRef]

34. Zhang, L.; Luo, L.; Zhang, S. Adsorption of phenanthrene and 1,3-dinitrobenzene on cation-modified clay minerals. Colloid Surf. A Physicochem. Eng. Asp. 2011, 377, 278-283. [CrossRef]

35. Guégan, R.; Giovanela, M.; Warmont, F.; Motelica-Heino, M. Nonionic organoclay: A "Swiss Army knife" for the adsorption of organic micro-pollutants? Adv. Colloid Interface Sci. 2015, 437, 71-79. [CrossRef] [PubMed]

36. Gao, Y.; Gao, Z.; Sun, W.; Yin, Z.; Wang, J.; Hu, Y. Adsorption of a novel reagent scheme on scheelite and calcite causing an effective flotation separation. J. Colloid Interface Sci. 2017, 512, 39-46. [CrossRef] [PubMed]

37. Jiang, W.; Gao, Z.; Khoso, S.A.; Gao, J.; Sun, W.; Pu, W.; Hu, Y. Selective adsorption of benzhydroxamic acid on fluorite rendering selective separation of fluorite/calcite. Appl. Surf. Sci. 2018, 435, 752-758. [CrossRef]

38. Huang, X.; Xiao, W.; Zhao, H.; Cao, P.; Hu, Q.; Qin, W.; Zhang, Y.; Qiu, G.; Wang, J. Hydrophobic flocculation flotation of rutile fines in presence of styryl phosphonic acid. Trans. Nonferrous Met. Soc. China 2018, 28, 1424-1432. [CrossRef]

39. Xu, L.; Tian, J.; Wu, H.; Lu, Z.; Yang, Y.; Sun, W.; Hu, Y. Effect of $\mathrm{Pb}^{2+}$ ions on ilmenite flotation and adsorption of benzohydroxamic acid as a collector. Appl. Surf. Sci. 2017, 425, 796-802. [CrossRef]

40. Singh, B.K.; Mercier-Bion, F.; Lefevre, G.; Simoni, E. Effect of short chain aliphatic carboxylic acids for sorption of uranyl on rutile Zeta potential and in situ ATR-FTIR studies. J. Ind. Eng. Chem. 2016, 35, 325-331. [CrossRef]

41. Gregory, J. Review of chemistry of the solid-water interface. Processes at the mineral-water and particle-water interface in natural systems, by Werner Stumm. J. Colloid Interface Sci. 1993, 159, 520. [CrossRef]

42. Chen, P.; Zhai, J.; Sun, W.; Hu, Y.; Yin, Z.; Lai, X. Adsorption mechanism of lead ions at ilmenite/water interface and its influence on ilmenite flotability. J. Ind. Eng. Chem. 2017, 53, 285-293. [CrossRef]

43. Acharya, S.; Nayak, A. Separtion of D2EHPA and M3EHPA. Hydrometallurgy 1988, 19, 309-320. [CrossRef]

44. Koopal, L.K.; Lee, E.M.; Böhmer, M.R. Adsorption of cationic and anionic surfactants on charged metal oxide surfaces. J. Colloid Interface Sci. 1995, 170, 85-97. [CrossRef]

45. Socrates, G. IR Characteristic Group Frequencies; Wiley: New York, NY, USA, 1994.

46. Olu-Owolabi, B.I.; Unuabonah, E.I. Kinetic and thermodynamics of the removal of $\mathrm{Zn}^{2+}$ and $\mathrm{Cu}^{2+}$ from aqueous solution by sulphate and phosphate-modified bentonite clay. J. Hazard. Mater. 2010, 184, 731-738. [CrossRef] [PubMed]

47. Brzezinski, B.; Wojciechowski, G.; Urjasz, H.; Zundel, G. FT-IR study of the proton polarizability of hydrogen bonds and of the hydrogen-bonded systems in a di-Mannich base of 5,5'-dimethoxy-2,2'-biphenol. J. Mol. Struct. 1998, 470, 335-339. [CrossRef]

48. Deval, V.; Kumar, A.; Gupta, V.; Sharma, A.; Gupta, A.; Tandon, P.; Kunimoto, K.K. Molecular structure (monomeric and dimeric) and hydrogen bonds in 5-benzyl 2-thiohydantoin studied by FT-IR and FT-Raman spectroscopy and DFT calculations. Spectrochim. Acta Part A Mol. Biomol. Spectrosc. 2014, 132, 15-26. [CrossRef] [PubMed] 
49. Lin-Vien, D.; Colthup, N.B.; Fateley, W.G.; Grasselli, J.G. The Handbook of Infrared and Raman Characteristic Frequencies of Organic Molecules; Academic Press: London, UK, 1991; Chapter 1; pp. 1-7.

50. Meng, X.; Li, L.; Zou, K.; Liu, J. The effect of $\mathrm{SiO}_{2}$ on $\mathrm{TiO}_{2}$ up-conversion photoluminescence film. Opt. Mater. 2014, 37, 367-370. [CrossRef]

51. Aksakal, B.; Koç, K.; Yargı, Ö.; Tsobkallo, K. Effect of UV-light on the uniaxial tensile properties and structure of uncoated and $\mathrm{TiO}_{2}$ coated Bombyx mori silk fibers. Spectrochim. Acta Part A Mol. Biomol. Spectrosc. 2015, 152, 658-665. [CrossRef] [PubMed]

52. Jiang, Z.; Zhang, W.; Jin, L.; Yang, X.; Xu, F.; Zhu, J.; Huang, X. Direct XPS evidence for charge transfer from a reduced rutile $\mathrm{TiO}_{2}(110)$ surface to Au clusters. J. Phys. Chem. C 2007, 111, 12434-12439. [CrossRef]

53. Lee, C.Y.; Gong, P.; Harbers, G.M.; Grainger, D.W.; Castner, D.G.; Gamble, L.J. Surface coverage and structure of mixed DNA/alkylthiol monolayers on gold: Characterization by XPS, NEXAFS, and fluorescence intensity measurements. Anal. Chem. 2006, 78, 3316-3325. [CrossRef] [PubMed]

54. Mayer, J.T.; Diebold, U.; Madey, T.E.; Garfunkel, E. Titanium and reduced titania overlayers on titanium dioxide (110). J. Electron Spectrosc. Relat. Phenom. 1995, 7, 1-11. [CrossRef]

55. Kurtz, R.L.; Henrich, V.E. Comparison of Ti $2 p$ core-level peaks from $\mathrm{TiO}_{2}, \mathrm{Ti}_{2} \mathrm{O}_{3}$, and Ti metal, by XPS. Surf. Sci. Spectra 1998, 5, 179-181. [CrossRef]

56. Atla, S.B.; Chen, C.C.; Chen, C.Y.; Lin, P.Y.; Pan, W.; Cheng, K.C.; Huang, Y.M.; Chang, Y.F.; Jean, J.S. Visible light response of $\mathrm{Ag}^{+} / \mathrm{TiO}_{2}-\mathrm{Ti}_{2} \mathrm{O}_{3}$ prepared by photodeposition under foam fractionation. J. Photochem. Photobiol. A Chem. 2012, 236, 1-8. [CrossRef]

57. He, G.; Pan, G.; Zhang, M. Studies on the reaction pathway of arsenate adsorption at water-TiO ${ }_{2}$ interfaces using density functional theory. J. Colloid Interface Sci. 2011, 364, 476-481. [CrossRef] [PubMed]

58. Pena, M.; Meng, X.; Korfiatis, G.P.; Jing, C. Adsorption mechanism of arsenic on nanocrystalline titanium dioxide. Int. J. Environ. Sci. Technol. 2006, 40, 1257-1262. [CrossRef]

59. Leppinen, J.O. FT-IR and flotation investigation of the adsorption of ethyl xanthate on activated and non-activated sulfide minerals. Int. J. Miner. Process. 1990, 30, 245-263. [CrossRef]

60. Gu, J.; Yuan, C.; Xiao, Z.; Xu, M.; Huang, D.; Lu, Z. Atomic force microscopic observation of local supramolecular structure in phosphatidic acid langmuir blodgett films. J. Chin. Electron. Microsc. Soc. 1997, 5, 791-794. (In Chinese) 